\title{
HYPOCHOLESTEROLEMIC EFFECT AND PIGMENTS COMPOSITION OF HERBAL MEDICINE CONTAINING HIGHER AND LOWER PLANTS
}

\author{
LEENAWATY LIMANTARA ${ }^{a, b^{*}}$, RENNY INDRAWATIa,c, DIAN EKAWATI WIJAYA ${ }^{a}$, ERNI SULISTIAWATId, IRMA \\ HERAWATI SUPARTOd, RETNO DUMILAH ESTI WIJAYANTI', TATAS HARDO PANINTINGJATI \\ BROTOSUDARMO ${ }^{\mathrm{a}, \mathrm{c}^{*}}$
}

\begin{abstract}
aMa Chung Research Center for Photosynthetic Pigments, Universitas Ma Chung, Malang, Indonesia, bCenter of Urban Studies, Universitas Pembangunan Jaya, Banten, Indonesia, 'Chemistry Study Program, Faculty of Sains and Technology, Universitas Ma Chung, Malang,

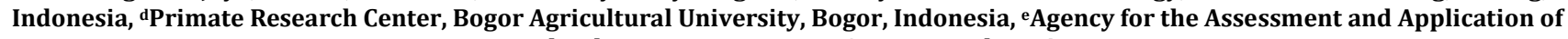
Technology, LAPTIAB-BPPT, Serpong, Indonesia

Email: leenawaty.limantara@upj.ac.id
\end{abstract}

Received: 05 Jul 2017 Revised and Accepted: 21 Sep 2017

ABSTRACT

Objective: The objective of this research was to investigate the antihypercholesterolemic activity of herbal medicine which consisted of pigmentrich simplicia from higher and lower plants, as well as to determine its pigments composition.

Methods: Sprague-Dawley male rats were randomly divided into five cholesterol-rich diet groups as well as one negative control group with a normal diet, in order to investigate its effect on plasma lipid. The new herbal formulation was administered orally to induced-rats at three dosage levels, whereas simvastatin was used as a comparable generic drug. Pigments composition was determined by means of reversed-phase highperformance liquid chromatography (HPLC) using gradient protocol, monitored with diode array detector at $430 \mathrm{~nm}$.

Results: The administration of herbal medicine was able to significantly reduce total plasma cholesterol and low-density lipoprotein-cholesterol $(p<0.05)$ at a dose of $312.5 \mathrm{mg} / \mathrm{kg}$ of body weight/day compared to positive control group, and hence the atherogenic index was also lowered. The chromatographic analysis of pigments determination and quantification are reported correspondingly to support the possible active compounds data of hypocholesterolemic property.

Conclusion: The results obtained in this research work indicated the potency of pigment-rich lower plants to substitute the obtrusive exploration and dominant use of higher plants for treating dyslipidemia.

Keywords: Herbal medicine, Lower plants, pigments, Cholesterol, Rats

(C) 2017 The Authors. Published by Innovare Academic Sciences Pvt Ltd. This is an open access article under the CC BY license (http://creativecommons.org/licenses/by/4.0/) DOI: http://dx.doi.org/10.22159/ijpps.2017v9i11.21133

\section{INTRODUCTION}

The use of herbal medication has been a part of the historical culture in Asian developing countries, such as China, India, Indonesia, Vietnam as well as the African countries. World Health Organization (WHO) recently defined herbal medicines as naturally occurring, plantderived substances with minimal or no industrial processing that have been used to treat illness within local or regional healing practices [1] In fact, herbal medicine is still the mainstay of about $75-80 \%$ of the world population, mainly in the developing countries, for primary health care [2]. In addition, nowadays the surveys conducted by some studies revealed that its uses even become prevalent in some developed countries (US, UK, Australia, European countries) and hence its scientific validation has become an ethical imperative [3-5].

As previously summarized by Tripathi and Singh, the most frequently used material come from higher plants, in the form of roots, rhizomes, leaves, seeds, barks, husks, fruits and flowers, including the whole plants [2]. To the best of our knowledge, lower plants have only little linkages in the commercially developed herbal medicine formulation. Macro-and microalgae are more widely engaged as sources of hydrocolloids, food ingredients, nutraceuticals, general supplements, even animal feeds, rather than medicinal purposes [6]. Algae actually have much faster and controllable growth rate, even almost all of its parts can be utilized since it has no wide variety of specialized tissues types. We are particularly concerned with the presence of photosynthetic pigments which have curative effect against leading cause of death such as cardiovascular disease (CVD). Some studies have obviously indicated the healing power of both macroalgae [7-12] and microalgae [13-16]
In this study, we focused on the anti-hypercholesterolemic action of a newly formulated herbal medicine that contains higher plant and lower plant in the diet-induced dyslipidemic animal model. Furthermore, chromatographic examinations of its acetonic extract will also be discussed subsequent to photosynthetic pigments properties in promoting hypocholesterolemic effect.

\section{MATERIALS AND METHODS}

\section{Materials}

The macroalgae, Padina australis Hauck, was harvested from the cultivation area in Sumenep, Madura Island, Indonesia, whereas the microalgae, Spirulina platensis (Gomont) Geitler was obtained as dried biomass (PT Synergy Worldwide Indonesia, Jakarta, Indonesia). Guazuma ulmifolia Lamk. was purchased from the regional centre for medicinal plants (UPT Materia Medika, Batu, Indonesia). All other chemicals used were of analytical grade.

\section{Preparation of herbal medicine formulation}

The newly proposed herbal medicine was prepared as blended powder of dried raw materials. Mass ratios of the macroalgae and the higher plants were same, whereas that of microalgae was a half, considering high protein content of the cells. Beside the microalgae, all raw materials were treated with clean water and blotted dry prior to freeze-drying in- $45{ }^{\circ} \mathrm{C}$ under high $(0.04 \mathrm{mbar})$ vacuum conditions (Labconco Corp., Kansas, USA) until the water content of the materials was less than $10 \%$ (wet basis). Low temperature and oxygen-free dehydration procedures were applied in order to maintain the heatlabile bioactive compounds, particularly the content of photosynthetic pigments. Furthermore, the simplicia was ground and sieved to a 
desired particle size $(180 \mu \mathrm{m})$. The formulation ratio was determined according to allowable dose of each component for human consumption based on best practices in marketplace. Then, the experimental doses were converted from human dose to those of rats in order to perform phamacological studies.

\section{Animals, diets, and experimental design}

Twenty four male Sprague-Dawley rats, $8 \mathrm{w}$ old, were obtained from National Agency of Drug and Food (BPOM-RI, Jakarta, Indonesia) and were housed individually in plastic cages with wood shavings bedding at $25{ }^{\circ} \mathrm{C}$ in a room with an automatically controlled 12-h light: dark cycle. Upon arrival, the rats were fed commercial laboratory animal diets (C. P. Diet 082, Perfect Companion Co. Ltd.,
Bangkok, Thailand) and accustomed to the facility until the body weights (BW) reached about 180-200 grams (14 w old). Then, the animals were randomly divided into six groups. The rats in the control group were fed normal diet (ND) (Control, $n=4$ ); the rats in the hypercholesterolemic group were fed a cholesterol-rich diet (atherogenic diet, $\mathrm{AD}$ ). The diet compositions are shown in table 1. At the same time, the induced-rats were orally gavaged with herbal medicine (HM) at a dose of $312.5 \mathrm{mg} / \mathrm{kg}$ BW/day (ADHM1), 625 $\mathrm{mg} / \mathrm{kg} \mathrm{BW} /$ day (ADHM2), $1250 \mathrm{mg} / \mathrm{kg} \mathrm{BW} /$ day (ADHM3), and simvastatin in $1.8 \mathrm{mg} / \mathrm{kg}$ BW (ADSV) while being fed the cholesterol-rich diet. One induced group without any medication was monitored as positive control (AD). During four weeks of experimentation, water was allowed ad libitum.

Table 1: Compositions of the experimental chow. ND, normal diet; AD, atherogenic diet

\begin{tabular}{lll}
\hline \% components & ND & \\
\hline feed base & 60 & AD \\
starch & 20 & 60 \\
lard oil & - & 15 \\
yolk & - & 10 \\
propylthiouracil & - & 5 \\
sodium cholate & - & 0.1 \\
water & 20 & 0.1 \\
\hline
\end{tabular}

Body weights were measured once in three days and feed intake was measured every day. Plasma lipid profiles were measured before the experiment (baseline) as well as after 14 and $28 \mathrm{~d}$ of experimentation. After the rats were deprived of food overnight, about $1,5 \mathrm{ml}$ of blood samples were collected from the vena caudalis of tail. Concentrations of total cholesterol (TC), total triglycerides (TG), and high-density lipoprotein cholesterol (HDL-c) in serum were determined by enzymatic colorimetric methods. Low-density lipoprotein cholesterol (LDL-c) was calculated using Friedewald equation $[17,18]$. The level of atherogenic index was accomplished according to the procedure outlined earlier (atherogenic index $=[\mathrm{TC}-$ HDL-c]/HDL-c) [19]. At the end of experimental period, the rats were anesthetized with sodium pentobarbital $(200 \mathrm{mg} / \mathrm{kg} \mathrm{BW})$ intracardially. Abdominal adipose tissue (epididymis, perirenal, and mesenteric adipose tissue) was excised and weighed. All treatments of animals in this study were approved by Animal Care and Use Committee (ACUC) Number R.07-13-IR issued by PT Bimana Indomedical, Bogor, Indonesia.

\section{Analytical methods}

\section{Chromatography analysis}

The analysis of total pigment content was carried out subsequent to extraction procedure using $100 \%$ acetone $(1: 10 \mathrm{w} / \mathrm{v})$. A small amount of calcium carbonate and ascorbic acid were also added in order to prevent any pigment degradation. The crude pigment extract was dried in vacuo and then dissolved in $1 \mathrm{ml}$ of acetone, microfiltered at $0.22 \mu \mathrm{m}$ (using PTFE membrane filter) and an aliquot of the filtered sample $(50 \mu$ l) was injected into HPLC with photodiode array detector (Shimadzu, Kyoto). The Shim-pack VPODS C-18 column was used and the detection wavelengths were set at $430 \mathrm{~nm}$ for detecting chlorophylls and carotenoids. The flow-rate was $1 \mathrm{ml} / \mathrm{min}$, and the gradient protocol lasted approximately 80 min in accordance with the previously described method [20]. The chromatograms were plotted using Plot32 software (arranged by A. Ikehata, Japan).

\section{Statistical methods}

The data were expressed as the mean \pm SEM. Multiple comparisons were performed with one-way ANOVA, and comparisons between negative control and cholesterol-rich treatments were statistically evaluated by the paired $t$-test. Significance was established at a $p$ value less than 0.05 . Moreover, Dunnett test was adopted to determine any significance between positive induced control and medication effects of simvastatin as well as herbal formulation.

\section{RESULTS AND DISCUSSION}

\section{Animal growth}

At the end of the experiment, there was no significant difference in BW among rats fed the normal diet and rats fed the cholesterol-rich diet (table 2). The growth curves (data not shown) indicate that high-fat diet promotes faster weight gain in the first $21 \mathrm{~d}$ of feeding period, and then diet intake rates were slightly decelerated. However, the results of the diet intake, growth, and BW after $28 \mathrm{~d}$ feeding showed no significant difference among induced groups, suggesting that neither the three dosage levels of herbal medicine nor simvastatin had an adverse effect on the growth of rats.

Table 2: Body and abdominal adipose tissue weight of rats

\begin{tabular}{|c|c|c|c|c|c|c|}
\hline & Control & AD & ADSV & ADHM1 & ADHM2 & ADHM3 \\
\hline Initial BW (g) & $192 \pm 5.71$ & $179 \pm 5.16$ & $198 \pm 5.66$ & $193 \pm 13.22$ & $192 \pm 2.80$ & $206 \pm 7.50$ \\
\hline Final BW (g) & $251 \pm 14.99$ & $208 \pm 7.43$ & $216 \pm 5.19$ & $224 \pm 14.61$ & $217 \pm 5.14$ & $229 \pm 8.21$ \\
\hline Abdominal adipose tissue weight (g/100 g BW) & $1.48 \pm 0.34$ & $2.20 \pm 0.24$ & $2.12 \pm 0.11$ & $2.46 \pm 0.28$ & $2.73 \pm 0.37$ & $2.21 \pm 0.10$ \\
\hline
\end{tabular}

Values are expressed as means \pm SEM of four rats per group and statistically evaluated with $5 \%$ significance level.

Control, rats with normal diet; AD, rats with atherogenic diet; ADSV, atherogenic diet with oral gavage of simvastatin; ADHM1, atherogenic diet with oral gavage of herbal medicine dose 1; ADHM2, atherogenic diet with oral gavage of herbal medicine dose 2; ADHM3, atherogenic diet with oral gavage of herbal medicine dose 3.
The weight of abdominal adipose tissue, which consists of epididymis, perirenal, and mesenteric adipose tissue, was observed to be lower in control group $(p>0.05)$. Our finding indicates that high-fat chow employed in this experiment might also have contribution in the abdominal fat accumulation. Nevertheless, 
statistical evolution did not prove any difference of fat accumulation among the medicated groups.

\section{Serum lipid profile alteration by cholesterol-rich diet}

It is known that cholesterol-rich diet is usually associated with hypercholesterol and atherogenesis condition. However, the influence of high-fat diet probably does not work similarly on each animal model. The adjustment of feed composition becomes crucial due to this obviousness. As a model for experimental atherosclerosis, the rat has limitation due to its resistance to hypercholesterolemia and the small size of the arterial vessels, hindering histologic or chemical studies. Nevertheless, with respect to lipoprotein metabolism, the rat is most widely studied species, and much of the methodology designed to investigate lipoprotein metabolism is readily applied to these animals [21]. Bile salts and propylthiouracil (antithyroid drug) are then often added into the experimental diet, in addition to high content of saturated fat and cholesterol, for developing the hypercholesterolemia and atherosclerosis. Sodium cholate was reported to improve the absorption and accumulation of cholesterol in vivo, and propylthiouracil plays a role as antithyroid drug to reduce the consumption of lipids [22-24].

The result of proxymate analysis of final chows applied in this study is shown in table 3. The cholesterol-rich diet contains about $10.85 \%$ higher of fat, whereas the other components are comparable.

Table 3: Proxymate data of the experimental chow. ND, normal diet; AD, atherogenic diet

\begin{tabular}{lll}
\hline \% components & ND & AD \\
\hline Fat & $3.36 \pm 0.18$ & $14.21 \pm 0.21$ \\
protein & $10.62 \pm 1.05$ & $11.20 \pm 0.22$ \\
crude fiber & $0.51 \pm 0.02$ & $2.05 \pm 0.31$ \\
Ash & $2.67 \pm 0.25$ & $2.72 \pm 0.09$ \\
carbohydrates* & $48.43 \pm 3.14$ & $45.36 \pm 0.28$ \\
\hline
\end{tabular}

Values are expressed as means \pm SEM. "by different

In the present study, all rats were examined for their TC, HDL-c, and TG as baseline value before the treatment, and they were further divided into groups without any significant differences of plasma cholesterols. After twenty eight days of probationary period, both plasma cholesterol (TC) and lipoprotein cholesterol (HDL-c, LDL-c) level were markedly higher compared to those in negative control group (table 4). The TC, LDL-c, and HDL-c levels of control group were somehow reduced after four weeks of treatment. We are unable to explain this contrivance since it is probably an unexpected metabolic responses against the compiled normal diet in certain species. Histopathological observation of this group confirms exceptionally mild up to mild hydropic degeneration of hepatocytes, while positive control group was characterized by moderate Kupffer cell hyperplasia.

Table 4: Serum lipid profile in rats fed cholesterol-rich diet. ND, normal diet; AD, atherogenic diet

\begin{tabular}{lllll}
\hline Lipids & ND (negative control) & & AD (positive control) & $\mathbf{4} \mathbf{~ w}$ \\
\cline { 2 - 5 } (mg/dL) & $\mathbf{0 ~ w}$ & $\mathbf{4} \mathbf{~ w}$ & $\mathbf{0 ~ w}$ & $148.75 \pm 3.71^{* *}$ \\
TC & $102.00 \pm 3.81$ & $73.75 \pm 5.81$ & $94.50 \pm 6.84$ & $88.80 \pm 3.00^{* *}$ \\
LDL-c & $37.30 \pm 0.64$ & $16.95 \pm 6.03$ & $32.50 \pm 3.52$ & $48.50 \pm 2.50^{*}$ \\
HDL-c & $54.00 \pm 3.83$ & $38.00 \pm 3.87$ & $47.50 \pm 2.40$ & $57.25 \pm 7.72$ \\
TG & $53.50 \pm 10.22$ & $94.00 \pm 31.63$ & $72.50 \pm 8.09$ & \\
\hline
\end{tabular}

Values are expressed as means \pm SEM of four rats per group. ${ }^{*} p<0.05$ vs. Control, ${ }^{* *} p<0.01$ vs. Control

The TG levels of positive control tend to be lower than those in normal control group, but there is no statistical significance. This finding is consistent with the previous observations by Zhang et al. [25] which noted that lowered serum triglyceride levels may be possible that the high fat diets contain some cholates. As bile salt, cholate is a ligand for the nuclear hormone receptor FXR, whose activity regulates the expression of multiple genes involved in lipoprotein metabolism. Among these genes are apoCII and apoCIII, whose alterations of expression could elucidate for the fact that the presence of cholate in the diet is associated with a lower TG than is the case for similar diets without cholate [26]. On the other hand, there was consistent inference of short-term studies that raising the carbohydrate content of the diet increases serum triacylglycerol concentration, and the magnitude of the effects depends on total amount and type of carbohydrate [27]. In this case, we partly added some starch into normal laboratory chow as fat compensation in atherogenic diet.

Most of cholesterol is an essential organic element inside the body. It performs at least three vital functions, which are to build the biological membranes, as the starting material for the synthesis of bile acid that works to digest food in the intestine, and to make steroid hormones and vitamin D. Y et, elevated concentration of cholesterol, especially plasma LDL-c, due to genetic disorders or improper diet, may lead to atherosclerosis and coronary heart disease. The significant increase of TC and LDL-c in rats fed high-fat chow overall indicated that the hyperlipidemic model of this study was successfully developed.

\section{Effects of herbal medicine on serum lipid profile}

According to the statistical evaluation, at the beginning of this study, all experimental groups did not differ from the normal group in serum lipid concentrations ( $p>0.05$ in all cases, data not shown). Fig. 1 shows the serum lipid levels at the end of the experiment. After four weeks of feeding, the TC and LDL-c concentrations of rats in treated groups showed a significant decrease compared with those of rats without any medication treatment $(p<0.05)$. However, no significant differences in HDL-c and TG levels $(p>0.05)$ was observed.

The smallest dose of herbal medicine might retard the elevation of TC caused by high-fat diet up to $13.45 \%$ compared to those in positive control group. It was demonstrated by Law et al. that a $10 \%$ reduction in serum cholesterol in men aged 40 has been reported to result in a 50\% reduction in heart disease within five years. Whereas, the same serum cholesterol reduction for men aged $70 \mathrm{y}$ can result in an average $20 \%$ reduction in heart disease occurrence in the next five years [28]. Eventhough there are some other well-published data which correlate lowered serum total cholesterol with deflation of heart disease prevalence [29-31], total serum cholesterol (TC) level actually represents several subcomponents, including the deleterious low-density lipoprotein (LDL) and very-low-density lipoprotein (VLDL) fractions, as well as the beneficial high-density lipoprotein (HDL) component. Thus, the effect of a specific dietary change on total serum cholesterol level might increase, decrease, or not influence risk of CVD, depending on which cholesterol components were changed [32]. 

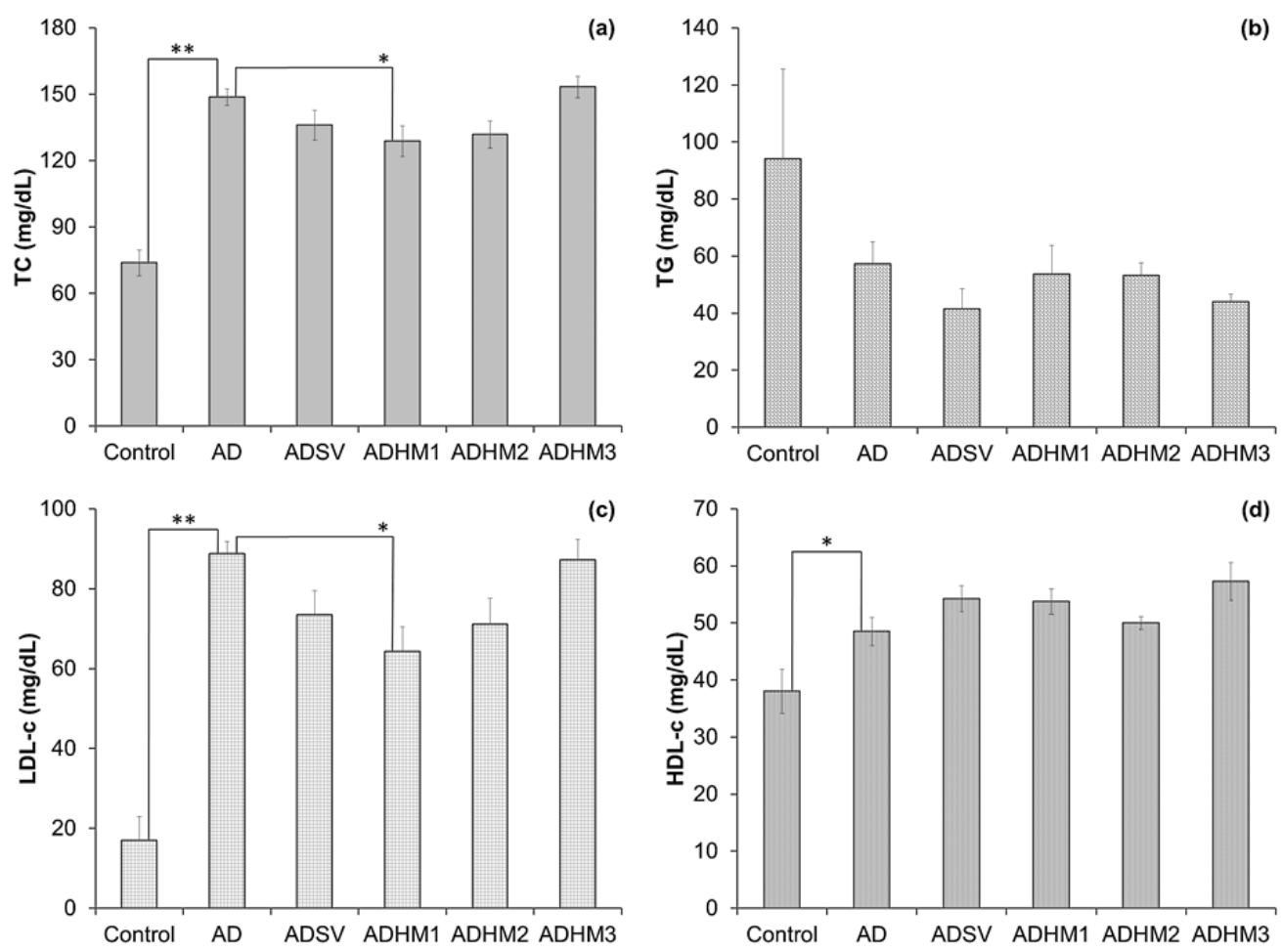

Fig. 1: Effects of herbal medication on serum lipid levels of rats fed cholesterol-rich diet for $28 \mathrm{~d}$. Control, rats with normal diet; AD, rats with atherogenic diet; ADSV, atherogenic diet with oral gavage of simvastatin; ADHM1, atherogenic diet with oral gavage of herbal medicine dose 1; ADHM2, atherogenic diet with oral gavage of herbal medicine dose 2; ADHM3, atherogenic diet with oral gavage of herbal medicine dose 3 . Values are expressed as means \pm SEM of four rats per group. Bars connecting with single star are significantly different $(p<0.05)$, whereas double stars represent greater significance $(p<0.01)$

It is widely accepted that in particular high LDL-c level bears the major risk factors for CVD, being the main cause of arterial blockage. LDL-c has ability to penetrate the endothelial wall and contributes to the development of foam cells, which form the core of a plaque (fatty deposit) in the walls of the arteries, leading to atherosclerosis. In addition, the presence of free radicals promotes oxidized LDL-c that also triggers an inflammatory process, accelerating vascular disease. Our results show that high concentration of LDL-c induced by hypercholesterolemia was significantly reduced about $27.65 \%$ by orally administering herbal medicine. Thus, it indicates that present medication can be as a candidate for the treatment of atherosclerosis by lowering serum LDL-c.

The influence of simvastatin was not statistically appeared at serum lipid profile after four weeks of treatment. Sparrow et al. suggested that simvastatin has anti-inflammatory and antiatherosclerotic activities independent of plasma cholesterol lowering [33]. Instead, its curative action was clearly evidenced in aortic cholesterol accumulation. Also, it should be noted that the discrepancies of various species may also contribute. Sometimes simvastatin even raised cholesterol levels, especially in higher continuous dose that stimulated the expression and activity of 3-hydroxy-3methylglutaryl coenzyme A reductase in the liver [25, 34, 35].

Moreover, it is interesting to find out that the leverage of herbal medicine seems to be dose dependent manner. In the present case, the best hypocholesterolemic response was shown by the modest dose at $312.5 \mathrm{mg} / \mathrm{kg}$ BW. The increase of medication dose gave no desirable effect in LDL-c lowering ability. This is probably due to reverse-effect of the plant compound as intact material was used during preparation. The detailed mechanism needs further investigation.

HDL-c,as the opponent, is the favored portion which is able to scavenge and remove LDL-c from the inner walls of blood vessels (endothelium). HDL-c reduces, reuses, and recycles LDL-c by transporting it to the liver to be reprocessed. Despite unmarked distinction of HLD-c levels among the treatment groups, we further observed the depiction of its enhancement after probation. Fig. 2 shows the alteration of LDL-c and HDL-c after we subtract the end levels with those in the beginning of treatment, as well as the calculated atherogenic indexes.

The inhibition of LDL-c increment was markedly found in simvastatin as well as the lowest dose of herbal medicine, and nearly significant in the middle dose. HDL-c elevation appeared as the essential property of both statin and natural compunds, since HDL-c levels in positive control rats were found in depleted state. On higher dose, there is another possibility of drug intervention to increase HDL-c first prior to reduce LDL-c, resulting in lowered atherogenic index. We suppose that prolonged probationary period is needed in order to elucidate the whole mechanism. Based on atherogenic index, both simvastatin and modest dose of herbal medicine gave significant larger intervention.

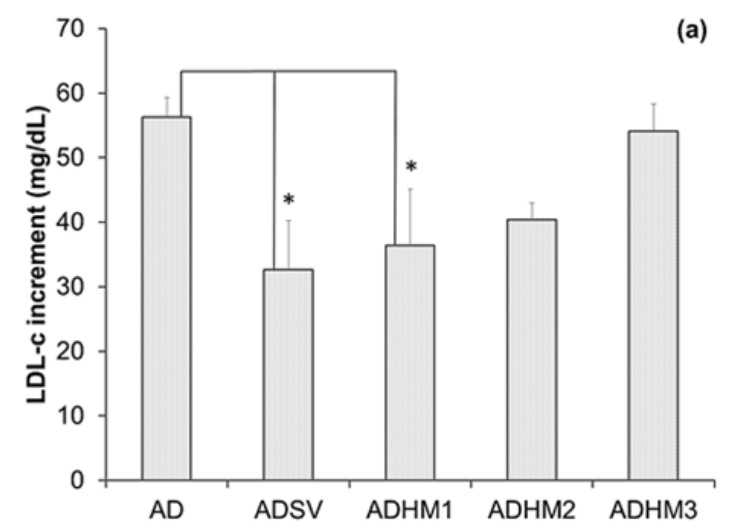



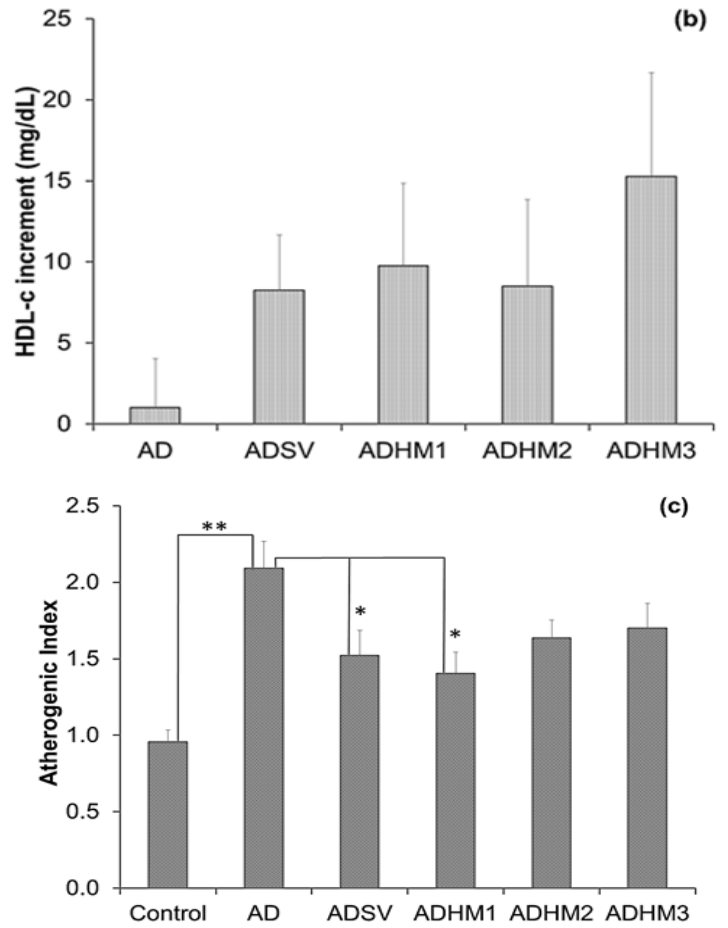

Fig. 2: The alteration of LDL-c and HDL-c levels during four weeks probation, as well as the calculated atherogenic index for each group. Control, rats with normal diet; $A D$, rats with atherogenic diet; ADSV, atherogenic diet with oral gavage of simvastatin; ADHM1, atherogenic diet with oral gavage of herbal medicine dose 1; ADHM2, atherogenic diet with oral gavage of herbal medicine dose 2; ADHM3, atherogenic diet with oral gavage of herbal medicine dose 3 . Values are expressed as means \pm SEM of

four rats per group. Bars connecting with single star are significantly different $(p<0.05)$, whereas double stars represent greater significance $(p<0.01)$

\section{Pigments compositions on herbal medicine formulation}

In our study, the curative action of newly formulated herbal medicine has been demonstrated in reducing the undesirable high level of TC and
LDL-c, as well as increasing the beneficial HDL-c level. Several natural products are usually recommended to impede hypercholesterolemia, such as cycloartenol, $\beta$-sitosterol, sitostanol, saponin, soybean protein indoles, propionate, mevinolin ( $\beta$-hydroxy- $\beta$-methylglutaryl coenzyme $A$ reductase inhibitor), dietary fiber, including the member of carotenoids [36]. Although we did not determine the detailed potential active compounds as well as its contents, we performed chromatography analysis in order to investigate its pigments composition, supposing that similar effects were observed in natural pigments or crude extracts from other sources.

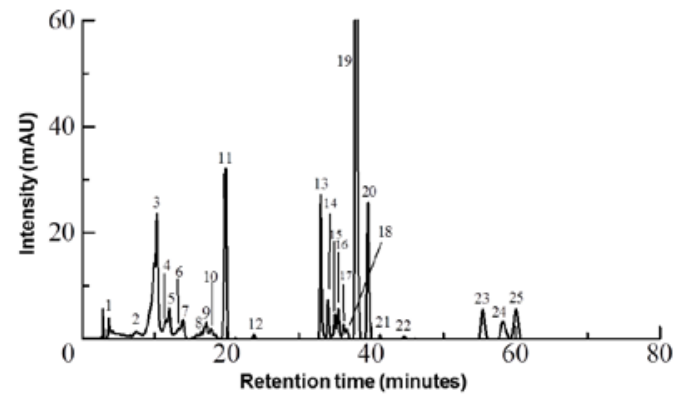

Fig. 3: High-performance liquid chromatogram (detection at $430 \mathrm{~nm}$ ) of acetone extract of herbal medicine formulation. The peak number corresponds to individual photosynthetic pigments listed in table 5

Fig. 3 shows the chromatographic profile of pigment analysis detected at $430 \mathrm{~nm}$ to identify the presence of both chlorophylls and carotenoids. Twenty five photosynthetic pigments were successfully identified according to the comparison of its absorption spectra with those in literatures, consisting of 13 compounds of chlorophylls and its derivatives and 12 carotenoids (table 5 ). The dominant pigments were chlorophyll $a$, lutein, chlorophyll $b$, trans-fucoxanthin, as well as some other minor pigments that have been found in significant amount (zeaxanthin and $\beta$-carotene). On individual analyses (data not shown), the macroalgae (Padina australis Hauck) has dominancy on chlorophyll $a$ and fucoxanthin, while microalgae Spirulina platensis (Gomont) Geitler is rich in chlorophyll $a$, zeaxanthin and $\beta$ carotene. As the higher plant, Guazuma ulmifolia Lamk. contributes in the presence of chlorophyll $a$, chlorophyll $b$, and lutein.

Table 5: Pigments identification based on their maximum absorbance

\begin{tabular}{|c|c|c|c|c|c|c|}
\hline No of peak & $t_{R}(\min )$ & \multicolumn{3}{|c|}{$\lambda$ maximum } & Pigments & Ref. \\
\hline 1 & 3.669 & 431.57 & - & 665.81 & chlorophylide sp. & 37,38 \\
\hline 2 & 7.477 & 406.50 & - & 665.81 & pheophorbide $a$ & 39 \\
\hline 3 & 10.325 & 451.64 & - & 466.71 & trans-fucoxanthin & 20 \\
\hline 4 & 11.573 & 414.02 & 435.33 & 466.71 & neoxanthin sp. & 37,38 \\
\hline 5 & 12.043 & 414.02 & 435.33 & 466.71 & neoxanthin sp. & 37,38 \\
\hline 6 & 13.344 & 415.27 & 440.35 & 469.22 & violaxanthin sp. & 37,38 \\
\hline 7 & 13.909 & 415.27 & 440.35 & 469.22 & violaxanthin sp. & 37,38 \\
\hline 8 & 16.416 & 400.24 & 422.79 & 447.88 & flavoxanthin & 37,38 \\
\hline 9 & 17.205 & - & 442.86 & - & cis-fucoxanthin & 20 \\
\hline 10 & 17.792 & 400.24 & 426.55 & 466.71 & carotenoid sp. & - \\
\hline 11 & 19.861 & 422.79 & 445.37 & 471.73 & lutein & 39,40 \\
\hline 12 & 23.744 & 432.82 & - & 466.71 & carotenoid sp. & - \\
\hline 13 & 33.013 & - & 466.71 & 649.53 & chlorophyll $b$ & 39 \\
\hline 14 & 34.016 & - & 466.71 & 653.37 & chlorophyll $b^{\prime}$ & 39,40 \\
\hline 15 & 34.976 & 420.28 & - & 653.37 & chlorophyll sp. & - \\
\hline 16 & 35.456 & 411.51 & 432.82 & 665.81 & chlorophyll $a$ derivative & $37-39$ \\
\hline 17 & 36.181 & 411.51 & 432.82 & 665.81 & chlorophyll $a$ derivative & $37-39$ \\
\hline 18 & 36.661 & 411.51 & 432.82 & 665.81 & chlorophyll $a$ derivative & $37-39$ \\
\hline 19 & 37.931 & 431.57 & 618.44 & 664.56 & chlorophyll $a$ & $37-39$ \\
\hline 20 & 39.563 & 432.82 & 618.44 & 664.56 & chlorophyll $a$ derivative & $37-39$ \\
\hline 21 & 41.237 & 432.82 & - & 665.81 & chlorophyll $a$ derivative & $37-39$ \\
\hline 22 & 44.629 & 432.82 & - & 665.81 & chlorophyll $a$ derivative & $37-39$ \\
\hline 23 & 55.477 & 407.75 & 608.44 & 665.81 & pheophytin $a$ & 37,38 \\
\hline 24 & 58.293 & 415.27 & 440.35 & 470.47 & $\alpha$-carotene & 41 \\
\hline 25 & 60.085 & - & 451.64 & 479.26 & $\beta$-carotene & 37,38 \\
\hline
\end{tabular}


Generally, carotenoids bear antioxidative roles in preventing inflammation of atheroslerosis incident [42]. Those activity and capability indeed depend on the diversity of chemical structure of carotenoids. For instance, the allenic bond of fucoxanthin was responsible for the higher antioxidant capacity [43]. Moreover, among thousand types of carotenoids, fucoxanthin has typical activity due to its involvement in body lipid metabolism. Its intervention could be mediated by altering lipid-regulating enzymes and uncoupling proteins in the visceral fat tissues and plasma adipokine levels [44]. Fucoxanthin may also upregulate the expression of uncoupling protein 1 in white adipose tissue, the gene responsible for metabolic thermogenesis to avoid an excess of fat accumulation [45]. Many other studies proved that fucoxanthin leads to elevation of HDL-level.

Lutein is commonly found carotenoid in green vegetables. Based on clinical investigation, Dwyer et al. demonstrated that in the coculture model of human intima, pretreatment of cells with lutein inhibited LDL-induced migration in a dose-dependent manner, while in the mose models, lutein supplementation reduced lesion size, and hence being protective agains the development of early atherosclerosis [46]. It was found more active than beta-carotene by its ability to reduce up to $80 \%$ arterial wall thickening [47]. It seems that lutein exerts potent antioxidant and antiinflamatory effects mainly in aortic tissue [48].

There is only a limited study that learn about possible inhibiting mechanism of chlorophylls in the formation of atherosclerosis. It is probably due to its unstable and easily-degraded characteristic. Yet, Vlad et al. clearly showed the effectiveness of Cuprofilin (modified chlorophyll with copper as the central complex) in decreasing serum cholesterol, triglycerides, as well as markedly diminishing lipid infiltration in the aorta [49]. These days cuprofilin or chlorophylin has been widely commercialized as general health supplement. The most possible mechanism arises from its chemical structure which is able to bind to environmental mutagens, therefore preventing inflammation.

\section{CONCLUSION}

In conclusion, we examined the effects of newly formulated herbal medicine composed of both higher and lower plants on serum lipid profile in diet-induced hypercholesterolemic rats. Our findings indicate that the herbal medicine significantly decreases the levels of total plasma cholesterol, LDL-c, as well as the atherogenic index. Thus, the combination of Guazuma ulmifolia, Padina australis, and Spirulina platensis is a promising candidate for new herbal medicine to prevent hypercholesterolemia. The presence of several prominent pigments in a considerable amount, i.e., fucoxanthin, lutein, and chlorophylls, may contribute as antioxidant to prevent inflammation, diminish lipid infiltration in the aorta, avoid the development of early atherosclerosis, increase HDL-c level, and hence, improve the serum lipid profile.

\section{ACKNOWLEDGEMENT}

This research project was supported by the Indonesian Ministry of Research, Technology, and Higher Education through the National Innovation System research grant (2013-2015) and Competitive Research (HIKOM) grant (2016-2017). Limantara as the principal investigator designed research, received funding, and directed research and wrote the paper. Indrawatiand Wijaya performed laboratory works, assays and wrote the paper. Sulistiawati and Suparto helped in animal study, whereas Wijayanti given accessed to the national research institute for performing assays. Brotosudarmo received Competitive Research grant for doing chromatography analysis, helped by Indriatmoko, carried out data interpretation and wrote the paper.

\section{CONFLICTS OF INTERESTS}

All authors declare no conflicts of interest

\section{REFERENCES}

1. Tilburt JC, Kaptchuk TJ. Herbal medicine research and global health: an ethical analysis. Bull World Health Organ 2008;86:594-9.

2. Tripathi P, Singh A. Natural resources from plants in the treatment of cancer: an update. Asian J Pharm Clin Res 2017;10:13-22.

3. Ernst E. Prevalence of use of complementary/alternative medicine: a systematic review. Bull World Health Organ 2000;78:258-66.
4. Ernst E, White A. The BBC survey of complementary medicine use in the UK. Complementary Ther Med 2000;8:32-6.

5. Foster DF, Phillips RS, Hamel MB, Eisenberg DM. Alternative medicine use in older Americans. J Am Geriatr Soc 2000;48:1560-5.

6. Oshima E. Medicinal uses of seaweed in traditional chinese medicine. In: Adams JD, Lien EJ. editors. Traditional Chinese medicine: scientific basis for its use. Cambridge: Royal Society of Chemistry; 2013. p. 238-63.

7. Hamza AH, Hegazi MM, Youness ER, Ahmed HH. Brown algae as a golden mine for treatment of liver fibrosis: a proposal based on experimental animal study. Int J Curr Pharm Rev Res 2015;6:225-36.

8. Hui F, Qiu-kuan W, Yun-hai H, Dan-dan R. Functional effect of dietary fiber from seaweed costaria costata residues on reduce in serum lipids in mice. J Dalian Ocean Univ 2012;3:004.

9. Yildiz G, Celikler S, Vatan O, Dere S. Determination of the antioxidative capacity and bioactive compounds in green seaweed Ulva rigida C. Agardh. Int J Food Prop 2012;15:11829.

10. Bocanegra A, Bastida S, Benedi J, Rodenas S, Sanchez-Muniz FJ. Characteristics and nutritional and cardiovascular-health properties of seaweeds. J Med Food 2009;12:236-58.

11. Shelar PS, Reddy SVK, Shelar GS, Kavitha M, Kumar GP, Reddy G. Medicinal value of seaweeds and its applications: a review. Cont J Pharm Toxicol Res 2012;5:1-22.

12. Awang AN, Ng JL, Matanjun P, Sulaiman MR, Tan TS, Ooi YBH. Anti-obesity property of the brown seaweed, Sargassum polycystum using an in vivo animal model. J Appl Phycol 2013;1-6. Doi 10.1007/s10811-013-0149-6.

13. Bhattacharjee M. Pharmaceutically valuable bioactive compounds of algae. Asian J Pharm Clin Res 2016;9:43-7.

14. Cheong SH, Kim MY, Sok DE, Hwang SY, Kim JH, Kim HR, et al. Spirulina prevents atherosclerosis by reducing hypercholesterolemia in rabbits fed a high-cholesterol diet. J Nutr Sci Vitaminol 2010;56:34-40.

15. Torres-Duran PV, Ferreira-Hermosillo A, Juarez-Oropeza MA. Antihyperlipemic and antihypertensive effects of Spirulina maxima in an open sample of mexican population: a preliminary report. Lipids Health Dis 2007;6:33.

16. Shaish A, Harari A, Hananshvili L, Cohen H, Bitzur R, Luvish T, et al. 9-cis- $\beta$-carotene-rich powder of the alga Dunaliella bardawil increases plasma HDL-cholesterol in fibrate-treated patients. Atherosclerosis 2006;189:215-21.

17. Friedewald WT, Levy RI, Fredrickson DS. Estimation of the concentration of low-density lipoprotein cholesterol in plasma, without use of the preparative ultracentrifuge. Clin Chem 1972;18:499-502.

18. Warnick GR, Knopp RH, Fitzpatrick V, Branson L. Estimating low-density lipoprotein cholesterol by the friedewald equation is adequate for classifying patients on the basis of nationally recommended cutpoints. Clin Chem 1990;36:15-9.

19. Matsubara M, Maruoka S, Katayose S. Decreased plasma adiponectin concentrations in women with dyslipidemia. J Clin Endocrinol Metab 2002;87:2764-9.

20. Limantara L, Heriyanto H. Studi komposisi pigmen dan kandungan fukosantin rumput laut cokelat dari perairan madura dengan kromatografi cair kinerja tinggi. ILMU KELAUTAN: Indonesian J Mar Sci 2010;15:23-32.

21. Mahley RW, Holcombe K. Alterations of the plasma lipoproteins and apoproteins following cholesterol feeding in the rat. J Lipid Res 1977;18:314-24.

22. Murphy C, Parini P, Wang J, Bjorkhem I, Eggertsen G, Gafvels M. Cholic acid as key regulator of cholesterol synthesis, intestinal absorption and hepatic storage in mice. BBA-Mol Cell Biol L 2005;1735:167-75.

23. Al-Noory A, Amreen A, Hymoor S. Antihyperlipidemic effects of ginger extracts in alloxan-induced diabetes and propylthiouracil-induced hypothyroidism in (rats). Pharmacogn Res 2013;5:157.

24. Kobayashi S, Terashima Y, Itoh $\mathrm{H}$. The effects of dietary chitosan on liver lipid concentrations in broiler chickens treated with propylthiouracil. J Poult Sci 2006;43:162-6.

25. Zhang X, Mao S, Luo G, Wei J, Berggren-Soderlund M, NilssonEhle $\mathrm{P}$, et al. Effects of simvastatin on apolipoprotein $\mathrm{M}$ in vivo and in vitro. Lipids Health Dis 2011;10:112. 
26. Getz GS, Reardon CA. Diet and murine atherosclerosis Arterioscler Thromb Vasc Biol 2006;26:242-9.

27. Fried SK, Rao SP. Sugars, hypertriglyceridemia, and cardiovascular disease. Am J Clin Nutr 2003;78:873S-80S.

28. Law MR, Wald NJ, Thompson S. By how much and how quickly does reduction in serum cholesterol concentration lower risk of ischaemic heart disease? Br Med J 1994;308:367.

29. Chen Z, Peto R, Collins R, MacMahon S, Lu J, Li W. Serum cholesterol concentration and coronary heart disease in population with low cholesterol concentrations. $\mathrm{Br}$ Med J 1991;303:276.

30. Martin M, Browner W, Hulley S, Kuller L, Wentworth D. Serum cholesterol, blood pressure, and mortality: implications from a cohort of 361662 men. Lancet 1986;328:933-6.

31. Johannesson M, Jonsson B, Kjekshus J, Olsson AG, Pedersen TR Wedel H. Cost effectiveness of simvastatin treatment to lower cholesterol levels in patients with coronary heart disease. New Engl J Med 1997;336:332-6.

32. Willett W. Nutritional epidemiology: monographs in epidemiology and biostatistics. Oxford: Oxford University Press; 1998.

33. Sparrow CP, Burton CA, Hernandez M, Mundt S, Hassing H, Patel $\mathrm{S}$, et al. Simvastatin has anti-inflammatory and antiatherosclerotic activities independent of plasma cholesterol lowering. Arterioscler Thromb Vasc Biol 2001;21:115-21.

34. Wang Y-XI, Martin-McNulty B, Huw LY, da Cunha V, Post J, Hinchman J, et al. Anti-atherosclerotic effect of simvastatin depends on the presence of apolipoprotein E. Atherosclerosis 2002;162:23-31.

35. Bea F, Blessing E, Bennett B, Levitz M, Wallace EP, Rosenfeld ME. Simvastatin promotes atherosclerotic plaque stability in apoE-deficient mice independently of lipid lowering. Arterioscler Thromb Vasc Biol 2002;22:1832-7.

36. Wang $\mathrm{H}, \mathrm{Ng} \mathrm{T}$. Natural products with hypoglycemic hypotensive, hypocholesterolemic, antiatherosclerotic and antithrombotic activities. Life Sci 1999;65:2663-77.

37. Prihastyanti M, Heriyanto, Limantara L, Trihandaru S. Photostability of the crude pigment extract from brown algae and identification of their degradation products. In: Limantara $\mathrm{L}$, Heriyanto, Sadtono E. editors. Proceeding of Natural Pigments Conference for South-East Asia. Malang; 2010. p. 213-9.

38. Indrawati R, Heriyanto, Limantara L, Susanto A. Study of pigments distribution in the stem, leaf, and vesicle of Sargassum filipendula C. Agardh, Sargassum polycystum C. Agardh and other Sargassum spp. from Madura waters by
HPLC. In: Limantara L, Heriyanto, Sadtono E. editors. Proceeding of Natural Pigments Conference for South-East Asia. Malang; 2010. p. 225-30.

39. Wijaya W, Heriyanto, Limantara L, Prasetyo B. The composition of pigments in three major teas by high performance liquid chromatography. In: Limantara L, Heriyanto, Sadtono E. editors. Proceeding of Natural Pigments Conference for SouthEast Asia. Malang; 2010. p. 237-43.

40. Palupi I, Kusmita L, Limantara L, Karwur F. Pigment composition of five Pandanus sp. In: Limantara L, Heriyanto, Sadtono E. editors. Proceeding of Natural Pigments Conference for South-East Asia. Malang; 2010. p. 294-302.

41. Hegazi MM, Ruzafa AP, Almela L, Candela ME. Separation and identification of chlorophylls and carotenoids from Caulerpa prolifera, Jania rubens and Padina pavonica by reversed-phase high-performance liquid chromatography. J Chromatogr A 1998;829:153-9.

42. Kale MA, Bindu SM, Khadkikar P. Role of antioxidants and nutrition in oxidative stress: a review. Int J Appl Pharm 2015;7:1-4.

43. Peng J, Yuan JP, Wu CF, Wang JH. Fucoxanthin, a marine carotenoid present in brown seaweeds and diatoms: metabolism and bioactivities relevant to human health. Mar Drugs 2011;9:1806-28.

44. Woo MN, Jeon SM, Shin YC, Lee MK, Kang M, Choi MS. Antiobese property of fucoxanthin is partly mediated by altering lipid-regulating enzymes and uncoupling proteins of visceral adipose tissue in mice. Mol Nutr Food Res 2009;53:1603-11.

45. Maeda H, Hosokawa M, Sashima T, Funayama K, Miyashita K. Fucoxanthin from edible seaweed, Undaria pinnatifida, shows antiobesity effect through UCP1 expression in white adipose tissues. Biochem Biophys Res Commun 2005;332:392-7.

46. Dwyer JH, Navab M, Dwyer KM, Hassan K, Sun P, Shircore A, et al. Oxygenated carotenoid lutein and progression of early atherosclerosis the los angeles atherosclerosis study. Circulation 2001;103:2922-7.

47. Alves-Rodrigues A, Thomas B. The role of lutein in the prevention of atherosclerosis. J Am Coll Cardiol 2002;40:835.

48. Kim JE, Leite JO, Smyth JA, Clark RM, Fernandez ML. A luteinenriched diet prevents cholesterol accumulation and decreases oxidized LDL and inflammatory cytokines in the aorta of guinea pigs. J Nutr 2011;141:1458-63.

49. Vlad M, Bordas E, Caseanu E, Uza G, Creteanu E, Polinicenco C. Effect of cuprofilin on experimental atherosclerosis. Biol Trace Elem Res 1995;48:99-109. 